\title{
The annotation of Information Structure in spoken Japanese
}

Emanuela Cresti, Massimo Moneglia

LABLITA, University of Florence, Italy

https://doi.org/10.36505/ExLing-2018/09/0001/000334

\begin{abstract}
This paper presents the main results of a pilot aimed at verifying the consistency of the Language into Act Theory model for the annotation of Information Structure in spoken Japanese. The segmentation of the Japanese speech flow into utterances through the detection of terminal prosodic breaks and the segmentation into information unit through non-terminal breaks works fine in Japanese. The main Information unit types characterizing the L-AcT approach (Comment, Topic, Parenthesis, Appendix) and their main properties, fit well with the Japanese data-set.

Key words: Spoken Japanese, Information Structure, Prosodic Structure.
\end{abstract}

\section{Introduction}

This paper presents a pilot aimed at verifying the consistency of the Language into Act Theory model (L-AcT, Cresti 2000; Moneglia \& Raso 2014; Cresti \& Moneglia 2018a) for the annotation of information structure in Japanese. The pilot is intended at grounding the development of an annotated mini-corpus to be stored in the IPIC Database (Panunzi \& Gregori 2012) which is devoted to the Crosslinguistic Comparison of Information Structure. At present, IPIC stores resources of Italian, Brazilian and Spanish (Panunzi \& MalvessiMittmman 2014; Nicolas-Martinez \& Lombán fothcaming)

The Japanese data set relies on the Nagoya University Conversation Corpus - NUCC (Fujimura et al. 2012) and corresponds to approx. 80 hours of conversation for 1.5 million transcribed morphemes. Transcripts are in Japanese characters, recently automatically transliterated into Latin characters. NUCC contains 129 natural dialogues and conversations between friends, family members and colleagues, representing a large variety of contexts. For this reason, it can be the source of a selection of samples fitting with the IPIC corpus design model (Cresti \& Fujimura 2018). The pilot considers around 100 excerpts derived from four recordings. ${ }^{1}$

L-AcT model foresee the alignment of each utterance in the corpus to its acoustic counterpart through the speech software WinPitch and the annotation of information structure according to a specific methodology and tagset (Moneglia \& Raso 2014). In 2. we will briefly sketch the main

ExLing 2018: Proceedings of $9^{\text {th }}$ Tutorial and Research Workshop on Experimental Linguistics, 28-30 August, Paris, Frannce 
assumptions for what regards the prosodic cues that are necessary to this end and we will verify the consistency of this model to the Japanese data set. More specifically, in 3 we will consider the criteria for the segmentation of the speech flow into utterances and in 4 . the segmentation of the utterance into information unit types.

\section{The general feature of the L-AcT model}

L-AcT assumes that the speech flow can be segmented into reference units by means of both pragmatic and prosodic cues. In this framework, a reference unit may belong to two types, respectively utterance and stanza. The utterance is defined as the counterpart of a Speech act (Austin 1962) and is the primary reference unit for speech (Biber et al. 1999). A stanza expresses the flow of thought (Chafe 1994) and corresponds to a sequence of week speech activities packaged together. ${ }^{2}$ The boundaries of both reference units are marked by prosodic breaks ('t Hart et al. 1990; Swerts 1999) that are perceived with the quality of being terminal (Moneglia \& Cresti 2005)

Every reference unit is composed of an Information Pattern which can be simple or complex. Each unit of the pattern necessarily corresponds to a prosodic unit. The prosodic units of a complex pattern are separated the one from the other by non-terminal breaks.

Given that information units match in one-to-one way to prosodic units, the prosodic annotation grounds the identification of information units in the flow of speech. Therefore, in order the model to be applied in a language, two preliminary operations are compulsory: 1) identification of terminal breaks; 2) identification of non-terminal breaks.

According to L-AcT, the core of the Information pattern is one specific information unit (Comment) devoted to the expression of illocutionary force. For this reason, a Comment unit is necessary and sufficient for a complete Information pattern. The latter may be simple, which is to say composed of only a Comment or complex. In Complex utterances other optional information unit types may support the Comment, each one corresponding to a dedicated prosodic unit and to a specific information function. Information functions are classified into two basic types, depending on whether they work in fulfilling the semantic content of the utterance or in its communicative support (Discourse markers).

Information unit types with their tags and formal definitions are detailed in Moneglia \& Raso 2014. The aim of the pilot is to verify the Adequacy of L-AcT model for the segmentation of spoken Japanese according to key operational principles. We will verify breaks detection, 
the consistency of the Comment principle, and the consistency of the main textual Information functions; i.e Topic (TOP), Parenthesis (PAR); Appendix (APC).

\section{Terminal breaks, non-terminal breaks and the pragmatic independence of the reference unit}

Although major prosodic breaks are prominent also to non-natives, they cannot really judge their terminal or non-terminal nature. The following two examples correspond to opposite judgements given by non-natives, both not fitting with speech act performance. The major break in figure 1 , which is connected to a rising contour, is perceived as a continuation, while the major boundary in figure 2 , showing a falling contour, is perceived terminal.

(1) J1:

十三? うち 十三...

jusan? uchi jusan::

thirteenth ? we thirteenth::

'tirteenth?' 'we (are) thirteenth...'

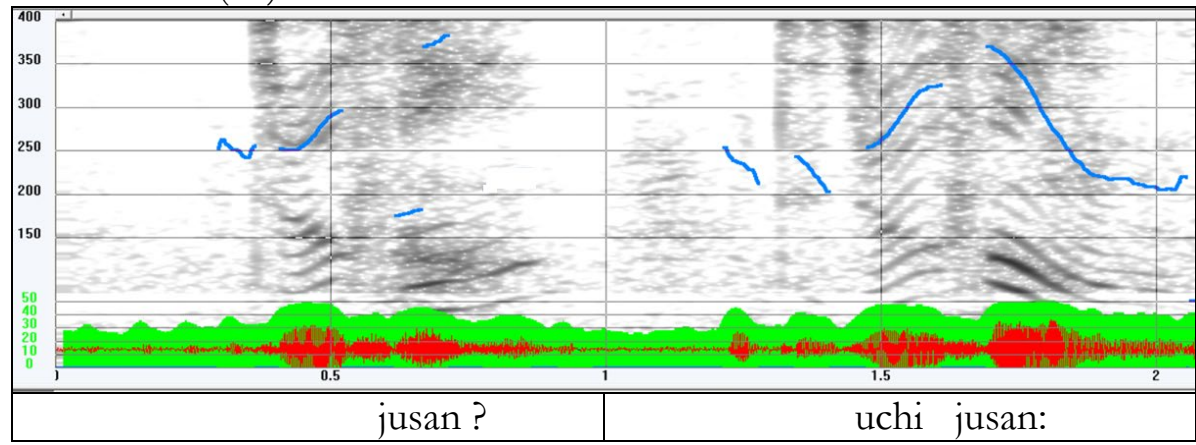

Figure 1. Terminal break with rising contour.

(2) *M3A18:

もうあんた 今ごろ 全部, 葉っぱ-が出そろってな-あかん よ。

mou anta imagoro zenbu / happa-ga desorotte na-akan yo //

already you now every / leave-SUB come-out must PR FIN //

'As a whole for now / leaves had to be already born'

As the transcript shows, competent speakers easily recognise that the first break in (2) is terminal, since it corresponds to a concluded speech activity (request of confirmation) that is followed by a second speech activity (supposition). If a stretch of speech can be interpreted in isolation as a speech act the prosodic break is judged terminal.

On the other way around, in (3) competent speaker do not assign the value of independent speech act to the first prosodic unit. The break is perceived non-terminal since it cannot be interpreted in isolation, and 
the prosodic unit is considered part of a sequence interpreted as selfconclusion.

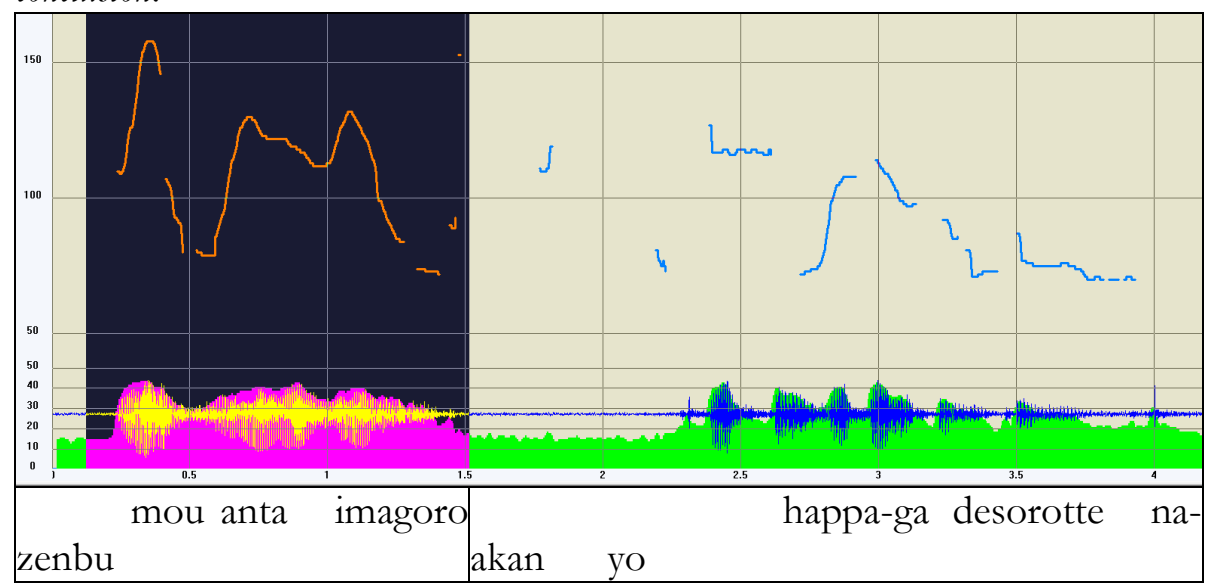

Figure 2. Terminal break with falling contour.

Therefore, the identification of the terminal quality in a major boundary does not follow from intrinsic prosodic properties (rising vs falling boundary tones), but strictly requires the access to the language competence which grounds the pragmatic interpretation. Based on this competence the linguist determines whether the prosodic unit can be interpreted or not in isolation. When it doesn't, the unit is part of a larger utterance and the perceived prosodic break is considered nonterminal. Therefore, the assignment of a value to prosodic breaks and pragmatic judgements go hand in hand.

\section{The Comment principle and the structure of information within the reference unit}

L-AcT foresees that when the utterance is segmented into information units these are marked by prosodic boundaries. (2) as well as the following examples, allow to verify: a) the segmentation of the utterance into information units according to non-terminal breaks detection; b) the correspondence of the information units to the typology of information function foreseen in L-AcT.

As we will see, the first prosodic unit in (2) corresponds to a Topic unit of a complex utterance, however, what is more interesting in (2) to our ends is the nature of the second unit. L-AcT assumes that within an utterance, characterized by an illocutionary value, one and only one unit identifies the information unit bearing the illocutionary information. We call Comment this unit. 
This core assumption of the theory is confirmed in (2). Indeed, listening in isolation to its second unit, competent speakers find that it can receive a pragmatic interpretation. The Comment principle hold in all terminated sequences of the pilot, grounding the application of the LAcT model. For instance, let's consider the following dialogue between wife and husband, where she complains about a delay in planting tulips and the husband note that indeed nothing flourished.

(3) *F1A8:

あ、と、チューリップとかて 今、もう植え-たら安いねんけどね 球根。

a to/PHA $\mathrm{chu}^{\wedge}$ rippu toka-te/TOP ima, mou/PAR ue -tara yasui-nen kedo ne /COM kyuukon / /APC

ah well / tulip such-as / right now / plant-if cheap but PR / bulb //

ah well / the tulips / if you, (had) already, planted (them) it would be less costly / the bulbs'

$\%$ ill: expression of disagreement

(4) *M3A:

チューリップなんか, 1つ-も出てへん やん うち

chu^rippu nanka /TOP hitotsu-mo de-te hen yan /COM uchi //APC

tulip such-as / anything go-out not isn't / our place //

(for what regards) tulips / nothing flourished / in our place //

$\%$ ill: ascertainment

As the F0 tracks in Figure 3 and 4 shows, both utterances are segmented into prosodic units by non-terminal breaks and present complex information patterns. Breaks are clear to perception and are marked by F0 resets.

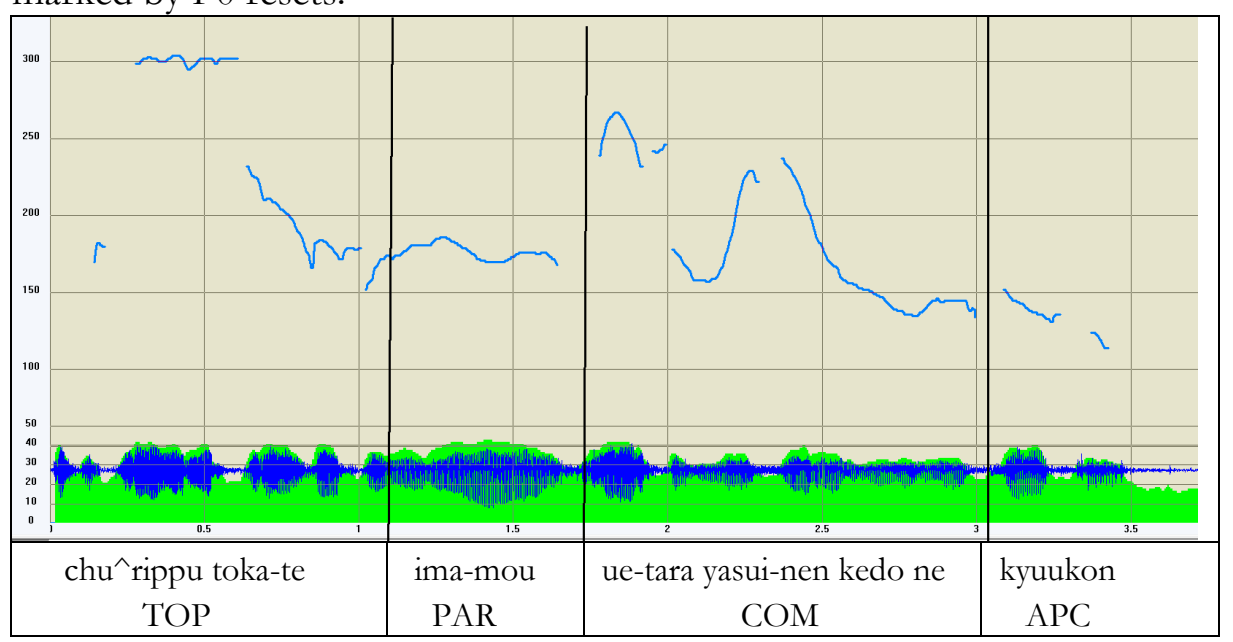

Figure 3. Prosodic units and F0 resets at non-terminal boundaries.

Working with competent speakers we first verified that one only unit play the role of Comment and can be interpreted in isolation and, in 
parallel, that all the other units can be erased from the signal without prejudice for the interpretability of the utterance. The Comment principle, works fine in Japanese.

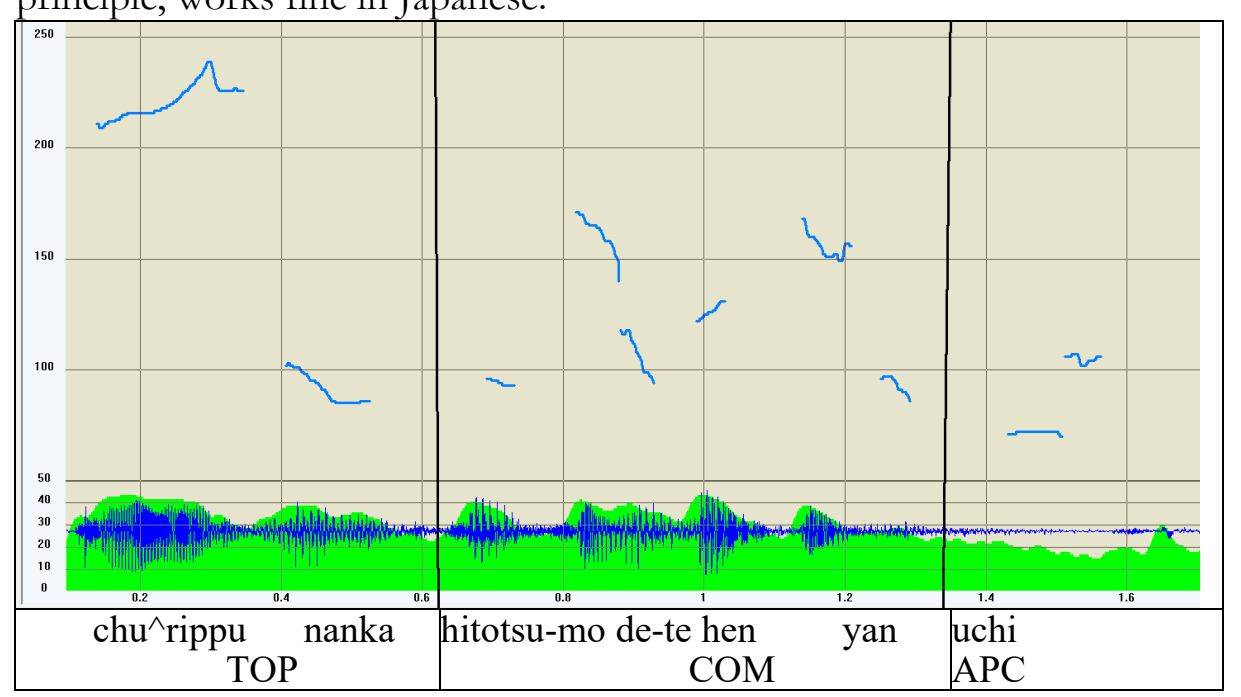

Figure 4. Prosodic units and F0 resets at non-terminal boundaries.

The information function of the Topic is defined in L-AcT at the pragmatic level. The Topic specifies to the addressee what the illocutionary activity performed by the Comment is about. From a formal point of view, it must precede the Comment and should bear a strong prosodic prominence (prefix prosodic form according to Signorini 2004; Mittman 2012; Cavalcante 2016; Cresti \& Moneglia 2018b).

Appendix and Parenthesis constitutes supplementary strategies foreseen in L-AcT for packaging information. The Appendix is a textual integration of the Comment's content, it has low semantic relevance and behaves as an adjunct at the end of the utterance. The Appendix occurs necessarily after the Comment unit and is performed via a prosodic unit of the suffix type, (with a low-falling profile and weak intensity). In this frame, it is sharply distinct from the Topic, since it does not specify the domain of relevance of the Comment. Topic/Comment and Comment/Appendix are well-formed prosodic patterns.

Parenthesis insert a metalinguistic evaluation in the utterance and it is characterised by a jump in F0 average with respect to the other units. Contrary to Topic and Appendix, Parenthesis does not have a canonical order with respect to the Comment; it can appear in whatever position, but not in first position, therefore the sequence Parenthesis/Comment is not a well-formed prosodic pattern. 
The above previsions of the L-AcT model match directly with Japanese data for what regards the informational role of Topic and Appendix, which respectively precedes and follow the Comment. The Topic unit is coherent with the informational definition of Topic: the self-conclusion in (2) is relative to the period of the year; the disagreement in (3) and the ascertainment in (4) regards "tulips". The Comment does not regard neither the "place" nor the "bulbs", which coherently with the function of Appendix integrates the information already given.

Japanese is a Topic-language (Li \& Thompson 1976; Shibatani 1982) and our spontaneous speech pilot confirm this. Also, from the prosodic point of view, Japanese fits with the general feature of the model. The prefix-root prosodic pattern supporting the Topic-Comment is a clear prosodic structure also in Japanese. The Topic bears a strong prosodic prominence, while the Appendix is weak and bears no movement.

Parenthesis strictly follow the properties foreseen in L-AcT. Competent speaker verified that Parenthesis in (3) can be erased without prejudice for the well formedness of the Topic Comment Appendix prosodic pattern. On the contrary, they also verified that, if the Topic unit is deleted, the resulting pattern (Parenthesis / Comment / Appendix) does not makes sense, this, despite the fact that "ima mou" [right now] might in principle be a reference for the act of disagreement.

\section{Conclusions}

Information units necessarily correspond to prosodic units as foreseen in the tradition of studies on Information Structure. Considering specifically terminal and non-terminal prosodic breaks highlight information units in spoken Japanese. These cues, that are very prominent to perception and can be verified with the support of F0 analysis are therefore viable for a large corpus annotation campaign. Beyond of that, L-AcT works fine in all its basic principles and specifically for the illocutionary definition of Comment; i.e the information unit specifying the illocutionary activity that permits the pragmatic interpretation of the utterance. More specifically the basic information unit types which pattern the utterance (Topic, Parenthesis and Appendix) structure the information in the utterances also in Japanese.

\section{Notes}

1. The acoustic source of NUCC transcripts is not delivered. The copy-right owner granted the wav files specifically for this pilot.

2. We will limit our argument to the utterance only in this paper. 


\section{References}

Austin, J. 1962. How to do things with words. London: Arnold.

Biber, D., Johansson, S., Leech, G., Conrad, S., Finnegan, E. 1999. The Longman Grammar of Spoken and Written English. London: Longman.

Cavalcante, F.A. 2015. The topic unit in spontaneous American English: a corpusbased study. Belo Horizonte: UFMG.

Cavalcante, F.A., Ramos, A.C. 2016. The American English spontaneous speech minicorpus. Architecture and comparability. CHIMERA: Romance Corpora and Linguistic Studies 3(2), 99-124.

Chafe, W. 1994. Discourse, consciousness, and time. University of Chicago Press.

Cresti, E. 2000. Corpus di italiano parlato. Firenze: Accademia della Crusca

Cresti, E. 2010. La Stanza: un'unita di costruzione testuale del parlato. In Ferrari, A. (Ed.), Sintassi storica e sincronica dell'italiano. Subordinazione, coordinazione e giustapposizione. Atti del X Congresso SILFI, 713-732. Firenze: Franco Cesati.

Cresti, E., Fujimura, I. 2018. The information structure of spontaneous spoken Japanese and Italian in comparison: a pilot study. In Manco, A. (Ed.) Le lingue extraeuropee e l'italiano: aspetti didattico-acquisizionali e sociolinguistici. Milano: Officinaventuno.

Cresti, E., Moneglia, M. 2018a. The illocutionary basis of information structure. In Adamou, E., Haude, K., Vanhove, M. (Eds) Information Structure in Lesserdescribed Languages. 359-402. Amsterdam: Benjamins.

Cresti, E., Moneglia, M. 2018b. The definition of the Topic within Language into Act Theory and its identification in spontaneous speech corpora. Revue Romane 5, 3062.

Fujimura, I., Chiba, S., Ohso, M. 2012. Lexical and grammatical features of spoken and written Japanese in contrast: Exploring a lexical profiling approach to comparing spoken and written corpora. In Raso, T., Mello, H., Pettorino, M. (Eds), Proc. of the International GSCP 2012 Conference: Speech and Corpora. 393-398. Firenze: FUP.

't Hart, J., Collier, R., Cohen, A. 1990. A Perceptual Study on Intonation. An Experimental Approach to Speech Melody. Cambridge University Press.

Panunzi, A. Gregori, L. 2012. DB-IPIC. An XML Database for the Representation of Information Structure in Spoken Language. In Mello, H., Panunzi, A., Raso, T. (Eds), Pragmatics and Prosody. Illocution, Modality, Attitude, Information Patterning and Speech Annotation. 133-150. Firenze University Press.

Panunzi, A., Malvessi-Mittmann, M. 2014. The IPIC resource and a cross-linguistic analysis of information structure in Italian and Brazilian Portuguese. In Raso, T., Mello, H. (Eds) 129-151. Spoken Corpora and Linguistic Studies, Amsterdam: Bejamins.

Nicolas-Martinez, C., Lombán, M. (forthcoming). Mini-Corpus del Español para DBIPIC, CHIMERA.

Signorini, S. 2005. Topic e soggetto in corpora di italiano parlato. Florence: University of Florence. (PhD Thesis).

WinPitch: https://www.winpitch.com/ 